\title{
O USO DE CASOS DE ENSINO NOS CURSOS DE ADMINISTRAÇÃO DE EMPRESAS NO BRASIL
}

\author{
Célia Beatriz Patto Martins \\ Alboni Marisa Dudeque Pianovski Vieira
}

\section{Resumo}

O uso de casos de ensino como ferramenta de suporte ao ensino nos cursos de Administração de Empresas e seus correlatos no Brasil tem crescido desde a sua introdução nos anos 1970. Os casos de ensino têm origem nos Estados Unidos da América, na Universidade de Harvard, com bons resultados de aprendizagem e o seu uso pode facilitar o processo de aprendizagem na sala de aula para solucionar problemas e situações empresariais reais. Este artigo, a partir de uma metodologia de revisão sistemática da literatura sobre o uso de casos de ensino nos cursos de Administração de Empresas e correlatos no Brasil, buscou levantar os temas de pesquisas mais comuns para, com isso, identificar possíveis lacunas e questões para futuras pesquisas. Os resultados demonstraram que a produção científica em periódicos nacionais, no campo estudado, é bastante reduzida e fragmentada.

Palavras-chave: casos de ensino; metodologia ativa; ensino de administração; método do caso.

\section{USE OF TEACHING CASES IN BUSINESS ADMINISTRATION COURSES IN BRAZIL}

\begin{abstract}
The use of teaching cases as a tool to support teaching in Business Administration courses and their correlates in Brazil has grown since its introduction in the 1970s. Teaching Cases started to be used in the United States of America, at Harvard University, with good learning results, and its use can facilitate the learning process in the classroom to solve real problems and business situations. This article, based on a systematic literature review methodology on the use of teaching cases in Business Administration courses and correlates in Brazil, sought to list the most common research topics in order to identify possible gaps and issues for future research. The results showed that the scientific production in national journals, in the studied field, is quite reduced and fragmented.
\end{abstract}

Keywords: teaching case methods; active methodology; administration teaching; case study.

\section{EL USO DE CASOS DOCENTES EN CURSOS DE ADMINISTRACIÓN EMPRESARIAL EN BRASIL}

\section{Resumen}

El uso de casos de enseñanza como una herramienta de apoyo para la enseñanza en cursos de Administración de Empresas y sus correlatos en Brasil ha crecido desde su introducción en la década de 1970. Los casos de enseñanza se originan en los Estados Unidos de América en la Universidad de Harvard, Los buenos resultados de aprendizaje y su uso pueden facilitar el proceso de aprendizaje en el aula para resolver problemas y situaciones comerciales reales. Este artículo, basado en una metodología de revisión sistemática de la literatura sobre el uso de casos de enseñanza en Administración de Empresas y cursos relacionados en Brasil, buscó plantear los temas de investigación más comunes, identificando posibles lagunas y problemas para futuras investigaciones. Los resultados mostraron que la producción científica en revistas nacionales, en el campo estudiado, es bastante reducida y fragmentada.

Palabras clave: casos docentes; metodología activa; docencia empresarial; método del caso. 


\section{INTRODUÇÃO}

A partir dos anos 1940, no Brasil, começou-se a discutir a necessidade da formação de profissionais voltados ao gerenciamento das empresas, para fazer frente ao movimento de industrialização do país. Em 1944, com o apoio do então presidente Getúlio Vargas, foi criada a Fundação Getúlio Vargas (FGV), como centro para a pesquisa e desenvolvimento do ensino na área de Administração de Empresas, o que culminou com a criação, em 1952, da Escola Brasileira de Administração Pública (EBAP) e, em 1954, da Escola de Administração de Empresas de São Paulo (EAESP). (CONSELHO FEDERAL DE ADMINISTRAÇÃO, [s. d.]; SALLES, SALLES, PINTO, 2015).

Desde então, os cursos de Administração de Empresas e correlatos têm sido criados e a procura por eles só tem crescido. Segundo o Censo da Educação Superior de 2017, conduzido e publicado pelo Instituto Nacional de Estudos e Pesquisas Educacionais Anísio Teixeira (INEP, 2018), eles representam cerca de 18\% de todos os cursos de graduação existentes em 2017 no Brasil, com cerca de 2 milhões de vagas ofertadas e 1,7 milhão de alunos matriculados. Esse valor representa aproximadamente $11 \%$ do total de matrículas efetuadas em instituições de Ensino Superior no Brasil (IES). Ao todo, o número de profissionais com título de bacharelado ou com cursos superiores específicos nas diversas áreas da Administração supera os 6,5 milhões (BOAVENTURA et al., 2018).

Especificamente, o curso de Administração de Empresas, desde a criação da EAESP, passou por muitas mudanças, assim como o próprio ambiente das empresas e dos negócios, mas foi somente em setembro de 1965 que a profissão de Administrador foi regulamentada e os respectivos Conselhos Federal e Regional foram criados (CONSELHO FEDERAL DE ADMINISTRAÇÃO, 2015).

Segundo a Resolução n. 4, de 13 de julho de 2005, do Conselho Nacional de Educação da Câmara de Educação Superior:

O Curso de Graduação em Administração deve ensejar, como perfil desejado do formando, capacitação e aptidão para compreender as questões científicas, técnicas, sociais e econômicas da produção e de seu gerenciamento, observados níveis graduais do processo de tomada de decisão, bem como para desenvolver gerenciamento qualitativo e adequado, revelando a assimilação de novas informações e apresentando flexibilidade intelectual e adaptabilidade contextualizada no trato de situações diversas, presentes ou emergentes, nos vários segmentos do campo de atuação do administrador. (CONSELHO NACIONAL DE EDUCAÇÃO, 2005, p. 2).

A relevância quantitativa dos cursos de Administração de Empresas e correlatos no Brasil por si só justificaria uma preocupação com a formação de seus egressos e seus docentes. No entanto, a complexidade da realização do objetivo constante nas diretrizes curriculares acentua a preocupação contínua com a formação desses profissionais e de seus professores, não só nos cursos de graduação como nos cursos de educação continuada e de pós-graduação, com a adoção de ferramentas e processos pedagógicos adequados.

Segundo Valdevino et al. (2017), muitas metodologias vêm sendo utilizadas nos cursos de Administração de Empresas e correlatos como, por exemplo, as aulas expositivas; aulas práticas no campo; trabalhos em grupo; palestras; seminários realizados por grupos de alunos; debates; estudos dirigidos; jogos de empresa e simulações; resolução de exercícios; o método do caso ou caso para ensino; entre outros. Esses autores afirmam que o método de caso ou caso para ensino é uma 
metodologia ativa que tira o docente do papel de figura central do processo pedagógico e dá esse papel ao aluno, tornando-o protagonista da sua própria aprendizagem.

A maioria das IES usa métodos tradicionais, que colocam o professor como centro na transmissão do conhecimento. Porém, considera-se que essas metodologias "[...] não desenvolvem nos estudantes o pensamento crítico a respeito das questões endereçadas" (SALLES, SALLES, PINTO, 2015, p. 3642).

Nicolini (2003, p. 51) entende que as novas realidades organizacionais - mudanças tecnológicas, mudanças da sociedade, mudanças políticas - precisam de administradores que:

[...] sejam capazes de reconhecer e definir problemas, equacionar soluções, pensar estrategicamente e ser criativo; que tenham iniciativa, vontade de aprender, abertura às mudanças, habilidades de negociação e consciência da qualidade e das implicações éticas de seu trabalho.

Para isso, acrescenta, o estudante que será o egresso dos cursos de Administração deverá ser um estudante ativo, o que não é comum nos modelos de aprendizagem mais utilizados nas IES. E se o objetivo maior for o desenvolvimento de competências de administrador para os egressos dos cursos de Administração de Empresas, observa Nicolini (2003, p. 54):

As competências desejáveis ao administrador, quando não são inatas, têm de ser desenvolvidas ao longo do curso - desenvolvimento que pressupõe o estudante como sujeito de seu próprio processo de formação. Há de se trabalhar os alunos como indivíduos que devem e têm de contribuir para o enriquecimento dos temas e abordagens desenvolvidos durante essa formação. $O$ estudo das organizações, muito rico, é de uma complexidade notável, o que traz uma dificuldade natural para apreendê-lo. Mesmo assim, ainda que complexo seja o assunto, o estudante que participa do projeto para sua formação terá a chance de desenvolver a consciência crítica que lhe permitirá uma melhor compreensão do fenômeno organizacional.

O modelo de ensino das disciplinas de Administração de Empresas no Brasil seguiu o modelo norte-americano de ensino, da mesma maneira que a maior parte das empresas seguiu o modelo norte-americano de gestão e negócios. As escolas norte-americanas de gestão e negócios há muito se utilizam de modelos de aprendizagem que fazem do aluno um elemento ativo do seu próprio processo de aprendizagem, destacando-se a aplicação de casos de ensino ou do método do caso. Nesse sentido, Iizuka $(2008$, p. 1) alerta para a necessidade de cuidados na "[...] transplantação de fórmulas prontas e a adoção despudorada de modismos", observação que se aplica à realidade brasileira.

Os casos de ensino têm origem no curso de Direito Comercial na Harvard Business School, EUA, sendo empregados pela primeira vez em 1908. Destaque-se que até hoje a Harvard Business School continua sendo a maior referência nesse método.

Esse método, segundo Roesch e Fernandes (2007), tem como objetivo desenvolver conhecimentos, habilidades e atitudes que são chaves para a prática gerencial eficaz; familiarizar o estudante com o ambiente das organizações e servir de ilustração prática para aulas. E esses objetivos são também os destacados nas Diretrizes Curriculares Nacionais para o curso de Administração de Empresas (BRASIL, 2005).

Os casos de ensino começaram a se popularizar no campo da Administração no Brasil a partir dos anos 70, quando surgiu a necessidade de serem desenvolvidos casos de ensino nacionais. Nos dias atuais, ainda não há produção significativa de casos nacionais, mas, desde 2007, a Associação Nacional de Pós-Graduação em Administração tem uma seção específica para a 
submissão desse tipo de trabalho em seu principal congresso, bem como na revista científica nacional da área, a Revista de Administração Contemporânea (RAC) (SALLES, SALLES, PINTO, 2015).

A Anpad também, em 2007, passou a promover o Encontro de Ensino e Pesquisa em Administração e Contabilidade (EnEPQ) para que se pudessem discutir os aspectos relacionados ao ensino e à pesquisa em Administração e, desde então, os casos de ensino vêm sendo pauta desses encontros (ANPAD, s. d.).

Além desse contexto próprio do campo da administração, há que se considerar a relevância do uso das metodologias ativas de aprendizagem, do ponto de vista da pedagogia em si. O caso de ensino é uma das opções facilitadoras para o uso de metodologia ativa em sala de aula. Segundo Berbel (2011, p. 29), as metodologias ativas colaboraram exatamente para a formação deste egresso mais autônomo e crítico, pois fazem com que ele ou ela:

[...] faça pesquisas, reflita e decida por ele mesmo, o que fazer para atingir os objetivos estabelecidos [...] utilizando experiências reais ou simuladas, visando às condições de solucionar, com sucesso, desafios advindos das atividades essenciais da prática social, em diferentes contextos.

Parece não haver dúvidas quanto à adequação do uso do caso de ensino como ferramenta útil e viável para auxiliar no desenvolvimento das competências do estudante de Administração de Empresas e futuro administrador. Parece também não haver dúvidas de que essa abordagem, assim como qualquer outra abordagem pedagógica, é mais eficaz quando considerado o contexto de sua aplicação. Para isso, faz-se necessária a adaptação dessa prática, mesmo que reconhecidamente de sucesso, como é o exemplo dos casos da Harvard Business School, levando em consideração o contexto histórico, político, social e econômico do país e das IES brasileiras (IIZUKA, 2008).

Frente a isso, justifica-se levantar a situação atual da produção científica a respeito desse tema no Brasil, para que se possa entender o que tem sido usado, como tem sido aplicado e questões ainda em aberto na nossa realidade.

A pergunta que, com base nesse contexto, orienta a execução desse estudo é: Como tem sido tratado pela comunidade científica da Administração de Empresas e da Educação no Brasil o tema da aplicação de casos de ensino?

\section{METODOLOGIA}

Para a abordagem metodológica, foi criado e seguido um procedimento rigoroso e sistemático. Para o atendimento ao objetivo de pesquisa, optou-se pela técnica de Revisão Sistemática, uma vez que ela se vale de procedimentos delineados sistematicamente para a busca e a avaliação de estudos, de modo trazer a consolidação dos conteúdos e das principais evidências do campo estudado.

A revisão sistemática de literatura tem sido utilizada como processo para identificar se uma prática ou uma pesquisa é nova ou não, bem como uma forma de localizar, selecionar, avaliar e sintetizar formalmente o corpo de conhecimento em um determinado campo científico (DENYER; TRANFIELD, 2009).

Tem sido especialmente relevante para os pesquisadores das ciências da saúde, a partir da necessidade de se praticar o que se chamou, nos anos 1970, de uma medicina baseada em evidências e que se consagrou chamar de prática baseada em evidência (PBE) (SAMPAIO, MANCINI, 2007). $\mathrm{Na}$ medicina, a PBE é definida como "[...] o uso consciente, explícito e sensato da melhor e mais atualizada evidência para tomar decisões a respeito dos cuidados com um paciente" (DENYER, 
TRANFIELD, 2009, p. 673). Foi a partir do sucesso dessa abordagem na medicina que a revisão sistemática se espalhou para os outros campos científicos.

A revisão sistemática como desenvolvida no campo da medicina, segundo Denyer e Tranfield (2009), deve ser adaptada para poder ser usada no campo dos estudos das organizações e da gestão, e para tanto eles propõem princípios a serem seguidos, tais como: transparência, inclusão a partir de critérios claramente estabelecidos, ser explicativa e heurística, de maneira a permitir julgamento de quem for utilizá-la.

Denyer e Tranfield (2009) propõem ainda cinco passos para se fazer a revisão sistemática. O primeiro passo, que é comum a qualquer outro tipo de pesquisa, é formular claramente uma pergunta que delimite o tema a ser estudado; o segundo passo é localizar os estudos que possam dar resposta à questão definida; o terceiro é selecionar os estudos que são mais relevantes usando critérios claros e bem definidos e avaliá-los também segundo critérios claros e bem definidos; o quarto é analisá-los e sintetizá-los para, finalmente como quinto e último passo, reportar os achados e, principalmente, detalhar as estratégias utilizadas para se chegar a eles.

Seguindo o caminho sugerido por Denyer e Tranfield (2009), essa revisão sistemática parte da questão colocada no capítulo introdutório - como tem sido tratado pela comunidade científica da Administração de Empresas e da Educação no Brasil o tema da aplicação de casos de ensino? e se desenvolve em quatro fases adaptadas da Declaração Prisma, processo usado pelas ciências da saúde para elaborar revisões sistemáticas e meta-análises (MOHER et al., 2009): identificação, seleção, elegibilidade e inclusão.

\section{Identificação}

O primeiro passo para a identificação das referências foi a escolha da base de dados para se efetuar a busca da literatura relativa ao tema, e o segundo, foi a definição das palavras-chaves a serem pesquisadas, bem como as lógicas de busca usando operadores lógicos adequados.

Inicialmente, foi escolhido como base para as buscas o Portal de Periódicos da Capes (CAPES, s. d.), visto que por meio dele pode se acessar mais de 45 mil títulos, 130 bases referenciais, além de outros documentos. A escolha foi direcionada pela maior probabilidade de se encontrar documentos que se referissem ao tema no Brasil, principalmente documentos em português.

Para a definição das palavras-chave em português que seriam utilizadas para a pesquisa, foi feita uma consulta inicial no sítio da Anpad que, como descrito anteriormente, possui divisão acadêmica que trata de ensino e pesquisa em Administração e Contabilidade (EPQ), na qual há uma área temática somente para tratar de casos para ensino (ANPAD, s. d.).

As palavras-chave escolhidas inicialmente foram: casos de ensino, casos para ensino e método do caso. Para que a busca abrangesse todos os termos de maneira adequada, foram usados operadores lógicos, que resultaram nas seguintes estruturas: "cas* de ensino", "cas* para ensino" e "metod? do cas*", sendo que este último foi filtrado para o idioma português, já que as palavras poderiam também trazer registros com o idioma espanhol, o que resultou num total de 142, 72 e 25 registros, respectivamente.

Essas palavras-chave foram apresentadas para outros dois pesquisadores da área da Administração, que concordaram com o potencial de cobertura do tema em estudo.

Foi adotada também a estratégia de não delimitação do período de tempo, pois o objetivo era a compreensão da evolução da temática ao longo de sua história, bastante recente no Brasil.

Essa fase foi concluída com eliminação de registros em duplicidade, o que resultou em 172 registros únicos. 
Seleção

A fase de seleção teve por objetivo selecionar os registros a partir de seu título e resumo, que trouxessem referências à aplicação do caso de ensino como metodologia ativa nos cursos relacionados à área de Administração de Empresas no Brasil, incluindo como construí-los e a aplicação em si em aula e excluindo casos em si. A exclusão dos casos em si se dá porque o interesse, que remete à pergunta inicial de pesquisa, não é avaliar o conteúdo dos casos, mas, sim, entender como tem sido estudada, no campo, a aplicação deles como ferramenta de metodologia ativa de ensino. A seleção resultou na eliminação de 131 referências que eram descrições de casos em si; quatro referências de fora do Brasil, 14 referências que não diziam respeito à área de Administração de Empresas ou correlatos e uma referência duplicada. Para ir à fase seguinte, foram selecionadas 22 referências.

\section{Elegibilidade}

Para ser elegível à inclusão para síntese final, o resumo de cada uma das referências foi analisado e somente aquelas publicadas em periódicos e anais classificados pela plataforma Qualis ${ }^{1}$ da Capes como A1, A2, B1 e B2 em uma das áreas de avaliação que são relacionadas ao tema estudado: Administração pública e de empresas, Ciências contábeis e turismo, Educação e ensino. Das 22 referências, apenas uma não atendeu ao requisito de elegibilidade.

\section{Inclusão}

O conteúdo das 21 referências foi então sintetizado conforme mostra a Tabela 1. Para auxiliar essa síntese, foram considerados alguns aspectos:

a) tipo de estudo;

b) o objetivo principal do estudo;

c) o foco principal do estudo, no sentido de se referir a uma ou mais etapas do processo de aplicação do caso de ensino, adaptado do que foi descrito por lizuka (2008): seleção do caso pelo professor; análise individual pelos alunos; preparação (questões, argumentos, dúvidas etc.); discussões em pequenos grupos; discussão do caso no grande grupo; finalização do caso que classificamos como "uso do caso de ensino"; somado a "preparação do professor"; "resultado do caso de ensino".

\footnotetext{
1 "Qualis é o conjunto de procedimentos utilizados pela Capes para estratificação da qualidade da produção intelectual dos programas de pós-graduação” (Qualis. Capes - Coordenação de Aperfeiçoamento de Pessoal de Nível Superior, [s. d.]).
} 


\section{Tabela 1: Síntese das referências}

\begin{tabular}{|c|c|c|c|}
\hline TÍTULO & TIPO DE ESTUDO & RESUMO & FOCO PRINCIPAL \\
\hline $\begin{array}{l}\text { Do método do caso ao case: A trajetória de } \\
\text { uma ferramenta pedagógica }\end{array}$ & Ensaio Teórico & $\begin{array}{l}\text { Diferencia as diversas terminologias - estudo } \\
\text { de caso, caso de ensino - origens e usos, no } \\
\text { exterior e no Brasil. }\end{array}$ & Conceitualização do caso de ensino \\
\hline $\begin{array}{l}\text { Notas sobre a construção de casos para } \\
\text { ensino }\end{array}$ & Ensaio Teórico & $\begin{array}{l}\text { Baseado em alguns casos de ensino, a autora } \\
\text { descreve os passos para a escrita de um caso } \\
\text { de ensino }\end{array}$ & Elaboração dos casos de ensino \\
\hline $\begin{array}{l}\text { Uso de casos para ensino em turismo: } \\
\text { Estratégia de ensino- aprendizagem para a } \\
\text { formação superior no Brasil }\end{array}$ & Estudo Exploratónio & $\begin{array}{l}\text { Descreve as características do método e a } \\
\text { partir de um caso da área do Turismo, no } \\
\text { sentido de estimular o uso nesse campo }\end{array}$ & Elaboração dos casos de ensino \\
\hline $\begin{array}{l}\text { Casos de ensino em administração pública: } \\
\text { Brasil - Portugal }\end{array}$ & Resenha de Livro & O livro traz casos de admu pública & Elaboração dos casos de ensino \\
\hline $\begin{array}{l}\text { Casos de ensino no Brasil: análise } \\
\text { bibliométrica e orientaçōes para autores }\end{array}$ & Revisão Bibliográfica & $\begin{array}{l}\text { Buscava elaborar uma guia para a elaboração } \\
\text { de casos, partindo da análise bibliométrica } \\
\text { dos casos produzidos no Brasil }\end{array}$ & Elaboração dos casos de ensino \\
\hline $\begin{array}{l}\text { A sala de aula e as empresas: Análise da } \\
\text { produção e da utilização de casos para ensino } \\
\text { em Administraçăo }\end{array}$ & $\begin{array}{l}\text { Revisão de literatura e Pesquisa } \\
\text { Qualitativa }\end{array}$ & $\begin{array}{l}\text { Buscava entender a produção de casos no } \\
\text { Brasil e o uso em uma Universidade Publica } \\
\text { brasileira com } 61 \text { professores }\end{array}$ & Elaboração dos casos de ensino \\
\hline $\begin{array}{l}\text { Ensino de Empreendedorismo: Utilização do } \\
\text { Business Model Generation }\end{array}$ & Estudo de Caso & $\begin{array}{l}\text { Aplicação do Business Model Generation } \\
\text { em uma disciplina em uma Faculdade de } \\
\text { São Paulo para gerar um caso de ensino }\end{array}$ & Elaboração dos casos de ensino \\
\hline $\begin{array}{l}\text { Como Escrever um Bom Caso para Ensino? } \\
\text { Reflexőes sobre o Método. }\end{array}$ & Ensaio Teórico & $\begin{array}{l}\text { A partir da análise dos casos apresentados no } \\
\text { Enanpad, fazem uma orientação sobre como } \\
\text { escrever um bom caso }\end{array}$ & Elaboração dos casos de ensino \\
\hline The case method in management sciences & Ensaio Teórico & $\begin{array}{l}\text { Discutir todos os aspectos desde a } \\
\text { construção até a aplicação de casos nas } \\
\text { ciências administrativas }\end{array}$ & Elaboração dos casos de ensino \\
\hline $\begin{array}{l}\text { Inserção de artigos tecnológicos e casos para } \\
\text { ensino na RAC }\end{array}$ & Editorial & $\begin{array}{l}\text { Trata-se de um editorial reportando a } \\
\text { migraçào de publicaçôes de um periodico } \\
\text { para outro }\end{array}$ & NA \\
\hline $\begin{array}{l}\text { Biblioteca de hipertextos para análise } \\
\text { organizacional: O sistema panteon como } \\
\text { plataforma aberta de desenvolvimento } \\
\text { colaborativo de estudos de casos online }\end{array}$ & Estudo de Caso & $\begin{array}{l}\text { Aborda o uso de tecnologia para a } \\
\text { elaboração, aplicação e analise de casos de } \\
\text { ensino }\end{array}$ & $\begin{array}{l}\text { No uso da tecnologia como suporte } \\
\text { para o desenvolvimento de } \\
\text { habilidades }\end{array}$ \\
\hline $\begin{array}{l}\text { Aprendizagem da docência: algumas } \\
\text { contribuições de L. S. Shulman }\end{array}$ & Ensaio Teórico & $\begin{array}{l}\text { Aborda o uso dos casos de ensino na ótica } \\
\text { de L. S. Shulman, um psicólogo } \\
\text { educacional professor emérito de Stanford, } \\
\text { cuja especialidade é o ensino. }\end{array}$ & Preparação do professor \\
\hline $\begin{array}{l}\text { Programa de mentoria online para } \\
\text { professores iniciantes: fases de um processo }\end{array}$ & Pesquisa Ação & $\begin{array}{l}\text { Pesquisa com } 56 \text { professores iniciantes, } \\
\text { onde o caso de ensino aparece rapidamente } \\
\text { como ferramenta }\end{array}$ & Preparação do professor \\
\hline $\begin{array}{l}\text { Casos de ensino como estratégia de } \\
\text { formação na temática ambiental }\end{array}$ & Pesquisa Qualitaiva Descritiva & $\begin{array}{l}\text { Pesquisa com Professores do Ensino } \\
\text { Fundamental no Parque Estadual da Serra do } \\
\text { Brigadeiro, em que usando o conehciemnto } \\
\text { dos próprios professores para o } \\
\text { desenvolvimento de casos para a educação } \\
\text { Ambiental. }\end{array}$ & Preparação do professor \\
\hline $\begin{array}{l}\text { Formação continuada: análise dos recursos e } \\
\text { estratégias de ensino para a educação } \\
\text { inclusiva sob a ótica docente }\end{array}$ & Pesquisa Ação & $\begin{array}{l}\text { Pesquisa Açao em escolas de ensino } \\
\text { fundamental }\end{array}$ & Preparação do professor \\
\hline $\begin{array}{l}\text { O desenvolvimento profissional de } \\
\text { professores e o uso de casos de ensino }\end{array}$ & Pesquisa Qualitaiva Descritiva & $\begin{array}{l}\text { Pesquisa com Professores do Ensino } \\
\text { Fundamental no Portal dos Professores da } \\
\text { UFSCar }\end{array}$ & Preparação do professor \\
\hline $\begin{array}{l}\text { A base de conhecimentos profíssionais para } \\
\text { o ensino: provocações à docência } \\
\text { universitária }\end{array}$ & Pesquisa Qualitaiva Descritiva & $\begin{array}{l}\text { Aborda o processo de preparação do docente } \\
\text { de engenharia. }\end{array}$ & Preparação do professor \\
\hline $\begin{array}{l}\text { Caso de Ensino como metodologia ativa em } \\
\text { administração }\end{array}$ & Pesquisa Quantitativa & $\begin{array}{l}\text { Objetivava entender a influência do uso de } \\
\text { casos de ensino no desenvolvimentos das } \\
\text { habilidades dos estudantes do curso de } \\
\text { graduação de uma escola de negócios de uma } \\
\text { universidade pública no Ceará }\end{array}$ & Resultado do caso de ensino \\
\hline $\begin{array}{l}\text { Jogos de empresas e metodo do caso: } \\
\text { contribuicoes ao processo de ensino e } \\
\text { aprendizagem em administracao }\end{array}$ & Experimento & $\begin{array}{l}\text { Comparou a aplicação de Jogos de Empresa } \\
\text { e Caso de Ensino na assimilação de } \\
\text { conhecimento de duas turmas de Adm numa } \\
\text { Universidae Pública }\end{array}$ & Resultado do uso caso de ensino \\
\hline $\begin{array}{l}\text { Estudos de caso no ensino da administracao: } \\
\text { o erro construtivo libertador como caminho } \\
\text { para insercao da pedagogia critica }\end{array}$ & Semi-Experimentos & $\begin{array}{l}\text { Usando a metodologia de construção e } \\
\text { aplicação de casos de ensino buscou-se } \\
\text { entender como o "erro e acerto" afetam a } \\
\text { aprendizagem. }\end{array}$ & $\begin{array}{l}\text { Uso e resultado do uso do caso de } \\
\text { ensino }\end{array}$ \\
\hline $\begin{array}{l}\text { Uso de estudos de caso em cursos de } \\
\text { graduacao em Administracao de Empresas }\end{array}$ & Pesquisa Quantitativa & $\begin{array}{l}\text { Pesquisa quantitava que a partir de } \\
\text { construtos criados pelos pesquisadores, } \\
\text { buscava entender a aceitação dos casos pelos } \\
\text { estudantes }\end{array}$ & $\begin{array}{l}\text { Uso e resultado do uso do caso de } \\
\text { ensino }\end{array}$ \\
\hline
\end{tabular}


Os 21 artigos sintetizados na Tabela 1 foram, portanto, como pede a metodologia, incluídos na análise final, e formaram a base da discussão que se segue e das considerações finais.

\section{DISCUSSÃO}

A primeira observação que se destaca é uma questão de terminologia. Há uma preocupação de alguns autores em diferenciar o caso de ensino do estudo de caso - metodologia de pesquisa qualitativa, também bastante utilizada no campo da Administração de Empresas - uma confusão que parece ser bastante comum em se adotando um termo pelo outro (ALBERTON, SILVA, 2018; DE ASSIS MENEZES, 2009; SERAFIM, OLIVEIRA, MOTTA, 2013).

A análise inicial que pode ser feita do resultado quantitativo desta revisão sistemática é que a principal preocupação da academia no campo da Administração tem sido a produção de casos de ensino brasileiros. Uma preocupação bastante válida, já que o contexto é citado como um fator importante na aplicação das metodologias ativas tanto para o engajamento dos alunos - o caso tratar de alguma empresa que faça parte da sua realidade - quanto para o docente - a maior probabilidade de ele conhecer a empresa do caso.

Foi essa mesma preocupação com a ausência de casos brasileiros que fez com que a Anpad criasse uma divisão acadêmica para avaliar casos escritos por pesquisadores brasileiros e funcionasse como um incentivo à produção de bons casos que se utilizassem da experiência e realidades brasileiras de gerenciamento de empresas. Também com essa mesma preocupação, a FGV-EAESP lançou, em 2010, a GVcasos - Revista Brasileira de Casos de Ensino em Administração (s. d.). Justifica-se, portanto, que da busca total realizada (a fase de seleção, descrita no capítulo 2), 80\% das referências eram descrições de caso e das referências efetivamente analisadas nessa revisão, 30\% eram sobre como escrever casos de ensino (ALBERTON, SILVA, 2018; ASSIS et al., 2013; ARAÚJO, REJOWSKI, LEAL, 2012; SERAFIM, OLIVEIRA, MOTTA, 2013; TREJO-PECH, WHITE, 2017; VALDEVINO et al., 2017).

Mesmo as publicações mais recentes, como em Alberton e Silva e em Valdevino et al. (ALBERTON, SILVA, 2018; VALDEVINO et al., 2017), a carência de bons casos de ensino brasileiros e os cuidados para escrevê-los ainda é assunto considerado relevante, afinal, o uso deles em sala de aula pressupõe, primeiramente, que eles existam em quantidade suficiente e de qualidade. Cabe aqui trazer a observação feita por Alberton e Silva (2018) para justificar a ainda relevância do foco no desenvolvimento e na disponibilização de casos brasileiros:

Apesar do crescimento da modalidade de casos para ensino como um produto científico e tecnológico na área de Administração, a nossa experiência como avaliadores, professores, editores e colaboradores da Divisão EPQ da ANPAD indica que muitos casos apresentam problemas em sua estruturação, tanto na delimitação do dilema como na elaboração das notas de ensino. (ALBERTON, SILVA, 2018, p. 748).

Ainda no que tange aos artigos que orientam a construção dos casos de ensino, dá-se destaque à importância das notas de ensino, como já mencionado. As notas de ensino orientam o docente na avaliação da adequação do caso para a situação de ensino-aprendizagem que é necessária ser desenvolvida e na resolução do caso em sala de aula. São, portanto, elementos importantes à preparação do docente (ALBERTON, SILVA, 2018; MOREIRA, BERNARDO, 2018; ROESCH, 2007). 
Por outro lado, as publicações que abordam a aplicação dos casos de ensino, em todo seu espectro - da preparação do professor ao uso efetivo em sala -, concentraram-se no campo da Educação $(60 \%)$ e são pulverizadas nestes aspectos.

Nesse último grupo de publicações, parece haver consenso de que o caso de ensino é igualmente útil como ferramenta para o desenvolvimento do aluno como também para a preparação do docente - de qualquer disciplina ou nível. No campo da preparação do docente, os artigos que tratavam do caso de ensino eram focados em professores do ensino fundamental, o que aponta para um problema na realização da busca de referências que não foram capazes de filtrar esses artigos, em fases anteriores. Por outro lado, mostra uma preocupação menor com a preparação dos docentes do ensino superior, seja na Administração ou em outro campo.

Os artigos que tratam do efetivo resultado trazido pelo uso dos casos de ensino são também pulverizados, porque a própria definição do que é o resultado esperado pode ser bem ampla, o que fez com que cada um dos autores que abordaram o tema definisse e construísse a sua própria abordagem para o resultado. Por exemplo, Serafim, Oliveira e Motta (2013) trataram o caso de ensino de forma comparativa aos jogos de empresa e com o uso associado a esse outro método; Assis et al. (2013) abordam o uso de casos de sucesso versus casos de fracasso e o papel que o erro tem no processo de aprendizagem; Valdevino et al. (2017), por seu turno, utilizam uma escala na qual se mede o "[...] desenvolvimento de habilidades nos estudantes", entre outras coisas, aplicada a um grupo de alunos de uma universidade matriculados em algumas disciplinas; Trejo-Pech e White (2017) tratam a aceitação do uso de casos de ensino pelos estudantes.

Apesar do crescimento dos cursos a distância, principalmente na área de Administração de Empresas e correlatos, muito pouco se menciona sobre a possível aplicação dos casos de ensino nesse cenário, exceto pelo artigo de Motta e Lima (2008), que menciona o uso de uma plataforma colaborativa para análise de casos.

\section{CONSIDERAÇÕES FINAIS}

A produção científica em periódicos nacionais classificados como A1, A2, B1 e B2 sobre a aplicação de casos de ensino no Brasil, no campo da Administração e da Educação, é bastante reduzida e fragmentada. Pode-se dizer que exceto pela preocupação da comunidade científica da Administração em produzir casos de ensino baseados em empresas e na realidade brasileiras com rigor, a preocupação com os demais elementos - preparação do docente, aplicação em sala de aula e avaliação dos resultados - parece ser irrelevante nos artigos publicados nos periódicos da área. A mesma conclusão pode ser tomada para a área da Educação, visto que os artigos que trazem o tema são, em sua maioria, voltados aos docentes do Ensino Fundamental.

As lacunas de pesquisa que advêm desta revisão sistemática são, portanto, nessas três grandes áreas: preparação do docente, aplicação em sala de aula e avaliação dos resultados.

Se somente a ausência de estudos relevantes que cubram essas três grandes áreas no Brasil não justifica o desenvolvimento de pesquisas, há que se destacar, novamente, a relevância, ao menos no aspecto quantitativo, que os cursos de Administração de Empresas e correlatos têm no Brasil. Conforme mencionado no capítulo introdutório, o Censo da Educação Superior de 2017, conduzido e publicado pelo Inep (INEP, 2018), demonstra que os cursos de Administração representavam cerca de $18 \%$ de todos os cursos de graduação existentes em 2017, no Brasil. São cerca de 2 milhões de vagas oferecidas e 1,7 milhão de alunos matriculados e qualquer ferramenta que reconhecidamente auxilie na formação deste contingente deveria ser tomada por relevante pelo seu próprio campo científico. 
Na preparação do docente para a aplicação dos casos de ensino poder-se-ia explorar além da construção das notas de ensino como parte do caso de ensino, item fundamental, mas já com cobertura do tema pela divisão temática de ensino e pesquisa da Anpad. Uma possibilidade exequível seria pesquisar o processo ou os processos utilizados por docentes de diferentes tipos de IES, com suas diferentes matrizes curriculares que se utilizam de casos de ensino. Entender as práticas adotadas, em que disciplinas, com que contexto em sala de aula, com suas dificuldades e resultados alcançados, de maneira científica e sistemática, traria corpo a esse campo.

Do mesmo modo, poder-se-ia evoluir o entendimento sobre a aplicação em sala de aula, sob a perspectiva dos discentes e, também, dos docentes, como alguns dos (poucos) estudos levantados nessa revisão. Esse tipo de estudo, apesar de pouco relevante nos periódicos nacionais, parece ter alguma relevância em encontros acadêmicos, como congressos e eventos temáticos.

A grande área de resultados da aplicação do método parece ser a de maior dificuldade de desenvolvimento, pois remete à discussão de um tema ainda mais complexo, que é a definição do que seja o resultado de um processo de aprendizagem, mesmo que nos limitemos a traduzir em algum aspecto mensurável o que traz a diretriz curricular de um curso superior. As referências que tentaram fazer estudos mais quantitativos e relacionados a resultados da aplicação apresentaram-se como limitadas pela sua própria abrangência e amostragem.

Por último, a quase total ausência de menção ao ensino a distância, uma das modalidades de ensino que mais cresce no Brasil e que em termos de matrículas já representa mais de $20 \%$ do total das matrículas no ensino superior (AGÊNCIA BRASIL, 2018), também representa uma lacuna com grande potencial para estudos futuros.

A revisão executada, apesar de seguir os critérios definidos para uma revisão sistemática, também apresenta limitações quanto à abrangência, pois as escolhas podem ter privilegiado apenas um pequeno número de periódicos e excluído outras publicações com conteúdo relevante. Uma alternativa a esse aspecto, que não foi explorada, seria uma busca inicial mais abrangente a partir de uma base aberta, como o Google Acadêmico.

Vale concluir que o caso para ensino é só uma das possíveis metodologias ativas a serem usadas para se alcançar o que propõem as diretrizes curriculares dos cursos de Administração de Empresas e seus correlatos, justificado pelo sucesso da aplicação no local de sua origem que tem inspirado quem atua neste campo, mas todo o processo pedagógico deve ser pensado de maneira integrada, não só na modalidade presencial, mas também na modalidade a distância.

O artigo de Nicolini (2003) - que apesar de ter sido escrito há 15 anos, momento em que se publicou uma das revisões das diretrizes curriculares do curso - já nos alertava sobre a necessidade da utilização de metodologias inovadoras e com a preparação adequada e interdisciplinar das equipes de trabalho para que não houvesse a estagnação numa "[...] concepção bancária já explicitada por Paulo Freire, e que resultaria nas mesmas 'fábricas de administradores' construídas após as duas primeiras regulamentações" (NICOLINI, 2003, p. 54), ou seja, sem que de fato se tenham os egressos com as competências desejadas nas letras das diretrizes curriculares, um profissional capaz de julgar criticamente as situações e propor soluções para os problemas de gestão que se apresentam a ele no exercício de sua profissão.

\section{REFERÊNCIAS}

ALBERTON, Anete; SILVA, Anielson Barbosa da. Como escrever um bom caso para ensino? Reflexões sobre o método. Revista de Administração Contemporânea, São Paulo, v. 22, n. 5, p. 745-761, 2018. 
AGÊNCIA BRASIL. Educação a distância cresce 17,6\% em 2017; maior salto desde 2008. Disponível em http://agenciabrasil.ebc.com.br/educacao/noticia/2018-09/educacao-distanciacresce-176-em-2017-maior-salto-desde-2008. Acesso em 30 jan.2019.

ANPAD - Associação Nacional de Pós-Graduação e Pesquisa em Administração. Disponível em http://www.anpad.org.br/ anpad/sobre_div_academicas.php. Acesso em 17 jan. 2019.

ARAÚJO, Maria Valéria Pereira de; REJOWSKI, Mirian; LEAL, Sérgio Rodrigues. Uso de casos para ensino em turismo: estratégia de ensino-aprendizagem para a formação superior no brasil. Revista Brasileira de Pesquisa em Turismo, São Paulo, v. 6, n. 1, p. 109-126, 2012.

ASSIS, Lilian Bambirra de; PAULA, Ana Paula Paes de; BARRETO, Raquel de Oliveira; VIEGAS, Glauce. Estudos de caso no ensino da administração: o erro construtivo libertador como caminho para a inserção da pedagogia crítica. Revista de Administração Mackenzৃie, São Paulo, v. 14, n. 5, p. 4473, 2013.

BERBEL, Neusi Aparecida Navas. As metodologias ativas e a promoção da autonomia de estudantes. Semina: Ciências Sociais e Humanas, v. 32, n. 1, p. 25-40, 2011.

BOAVENTURA, Patrícia Silva Monteiro; SOUZA, Lucas Lopes Ferreira de; GERHARD, Felipe; BRITO, Eliane Pereira Zamith. Desafios na formação de profissionais em Administração no Brasil. Administração: Ensino e Pesquisa, v. 19, n. 1, p. 1-31, 2018. Disponível em https://www.researchgate.net/publication/323270104_Desafios_na_formacao_de_profissionais em Administracao no Brasil. Acesso em 5 fev. 2019.

BRASIL. CNE/CES. Resolução n. 04, de 13 de julho de 2005. Institui as Diretrizes Curriculares Nacionais do Curso de Graduação em Administração, bacharelado, e dá outras providências. Disponível em http://portal.mec.gov.br/cne/arquivos/pdf/rces004 05.pdf. Acesso em 20 jan. 2019.

CONSELHO FEDERAL DE ADMINISTRAÇÃO. História da profissão - CFA. Disponível em https://cfa.org.br/administracao-administracao/administracao-historia-da-profissao/. Acesso em 25 nov. 2018.

CONSELHO FEDERAL DE ADMINISTRAÇÃO. 50 anos que fizeram história. Brasília, 2015. Disponível em http://bluehost1.cfa.org.br/wpcontent/uploads/2018/01/jubileu50anos completo segunda.pdf. Acesso em 25 nov. 2018.

DE ASSIS MENEZES, Maria Arlinda. Do método do caso ao case: a trajetória de uma ferramenta pedagógica. Educação e Pesquisa, São Paulo, v. 35, n. 1, p. 129-143, 2009.

DENYER, David; TRANFIELD, David. Producing a Systematic Review. In: BRYMAN, Alan; BUCHANAN, David A. (Ed.). The Sage Handbook of Organizational Research Methods, [s. 1.] Sage, 2009, p. 738.

IIZUKA, Edson Sadao. O método do caso de Harvard: reflexões sobre sua pertinência ao contexto brasileiro. XXXII Encontro da ANPAD. Anais... 2008 Disponível em http://www.anpad.org.br/admin/pdf/EPQ-A2874.pdf. Acesso em 21 jan. 2019.

MOHER, David; LIBERATI, Alessandro; TETZLAFF, Jennifer; ALTMAN, Douglas G.; The PRISMA Group. Preferred reporting items for systematic reviews and meta-analyses: The PRISMA statement. PLoS Med, v. 6, n. 7, 2009. Disponível em https://journals.plos.org/plosmedicine/article?id=10.1371/journal.pmed.1000097. Acesso em 20 jan. 2019. 
MOREIRA, Jefferson da Silva; BERNARDO, Josinaldo Carlos de Lima. A base de conhecimentos profissionais para o ensino: provocações à docência universitária. Revista Educação e Emancipação, São Luís, v. 11, n. 1, p. 78-104, 2018.

MOTTA, Gustavo da Silva; LIMA, Marcos Cerqueira. Biblioteca de hipertextos para análise organizacional: o Sistema Panteon como plataforma aberta de desenvolvimento colaborativo de estudos de casos on-line. Revista Eletrônica de Ciências Administrativas, Campo Largo, v. 7, n. 1, p. 19, 2008.

NICOLINI, Alexandre. Qual será o futuro das fábricas de administradores? Revista de Administração de Empresas, São Paulo, v. 43, n. 2, p. 44-54, 2003.

BRASIL. MEC. CAPES. Portal de periódicos da Capes. Disponível em http://www.periodicos.capes.gov.br. Acesso em 17 jan. 2019.

BRASIL. MEC. CAPES. Qualis. Capes - Coordenação de Aperfeiçoamento de Pessoal de Nível Superior. Disponível em http://www.capes.gov.br/component/content/article?id=2550:capesaprova-a-nova-classificacao-do-quali. Acesso em 18 jan. 2019.

REVISTA BRASILEIRA DE CASOS DE ENSINO EM ADMINISTRAÇÃO. Disponível em http://bibliotecadigital.fgv.br/ojs/index.php/gvcasos/index. Acesso em 29 jan. 2019.

ROESCH, Sylvia Maria Azevedo; FERNANDES, Francisco. Como escrever casos para o ensino de administração. São Paulo: Atlas S.A, 2007.

ROESCH, Sylvia Maria Azevedo. Notas sobre a construção de casos para ensino. Revista de Administração Contemporânea, São Paulo, v. 11, n. 2, p. 213-234, 2007.

SALLES, José A. A; SALLES, Luana F.; PINTO, Rosiele F. A Brief Overview of the Teaching Case Method in Brazil. Procedia - Social and Behavioral Sciences, v. 174, p. 3641-3644, 2015.

SAMPAIO, Rosana F.; MANCINI, Márcio C. Estudos de revisão sistemática: um guia para síntese criteriosa da evidência científica. Revista Brasileira de Fisioterapia, São Carlos, v. 11, n. 1, p. 83-89, 2007.

SERAFIM, Sheila; OLIVEIRA, Murilo Alvarenga; MOTTA, Gustavo da Silva. Jogos de empresas e método do caso: contribuições ao processo de ensino e aprendizagem em administração. Administração: Ensino e Pesquisa, São Paulo, v. 14, n. 4, p. 677-705, 2013.

BRASIL. MEC. INEP. Sinopse estatística educação superior 2017. Brasília: Inep, 2018. Disponível em http://portal.inep.gov.br/web/guest/sinopses-estatisticas-da-educacao-superio. Acesso em 28 jan. 2019.

TREJO-PECH, Carlos J. O.; WHITE, Susan V. The use of case studies in undergraduate business administration. Revista de Administração de Empresas, São Paulo, v. 57, n. 4, p. 342-356, 2017.

VALDEVINO, Antonio Messias; BRANDÃO, Halana Adelino; CARNEIRO, Jailson Santana; SANTOS, Ítalo Anderson Taumaturgo dos; SANTANA, Webert Jannsen Pires de. Caso para ensino como metodologia ativa em administração. Revista Pensamento Contemporâneo em Administração, Rio de Janeiro, v. 4, n. Especial, p. 1-12, 2017. 


\section{Informações das autoras}

Célia Beatriz Patto Martins

Pontifícia Universidade Católica do Paraná

E-mail: celiabeatrizpattomartins@gmail.com

ORCID: https://orcid.org/0000-0003-4853-7512

Link Lattes: http://lattes.cnpq.br/7608603616160493

Alboni Marisa Dudeque Pianovski Vieira

Pontifícia Universidade Católica do Paraná

E-mail:alboni@alboni.com

ORCID: http://orcid.org/0000-0003-3759-0377

Link Lattes: http://lattes.cnpq.br/0198429449537597 